\title{
Formulation Development and Evalua Tion of Fluoxetine Effervescent Floating Tablet
}

\author{
Pakhale Nilesh V. ${ }^{1 *}$, Gondkar S.B ${ }^{1}$, Saudagar R.B ${ }^{2}$ \\ ${ }^{1}$ Department of pharmaceutics, R.G. Sapkal College of pharmacy, Anjaneri, Nashik-422213, Maharashtra, India \\ 2 Department of Pharmaceutical Chemistry, R. G. Sapkal College of Pharmacy, Anjaneri, Nashik- 422213, Maharashtra, India
}

\begin{abstract}
The objective of the present study was to formulate and evaluate Effervescent Floating Tablet of Fluoxetine for the treatment of antidepressant agent. Tablets were prepared by direct compression using directly compressible polymers such as HPMC K4M, and Carbopol 934 were evaluated for drug-excipient compatibility, density, buoyancy test, swelling study, drug content and In-Vitro release profile. Sodium bicarbonate and citric acid were used producing effervescent base for buoyancy of tablets. Analysis of drug release from tablet indicates drug release by zero order, first order rate kinetics. No significant change was observed in physical appearance, drug content, floatability or in-vitro dissolution pattern after storage at $45^{\circ} \mathrm{C} / 75^{\circ} \mathrm{C} \mathrm{RH}$ for three months.
\end{abstract}

Keywords: Floating effervescent tablet, GIT, Fluoxetine, HPMC K4M, Carbopol 934.

Article Info: Received 06 July 2019; Review Completed 20 Aug 2019; Accepted 24 Aug 2019; Available online 30 Aug 2019

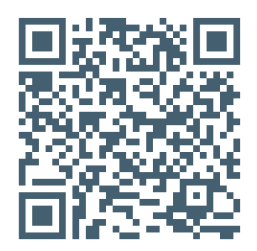

Cite this article as:

Pakhale NV Gondkar SB, Saudagar RB. Frmulation Development and Evalua Tion of Fluoxetine Effervescent Floating Tablet, Journal of Drug Delivery and Therapeutics. 2019; 9(4-A):358-366 http://dx.doi.org/10.22270/jddt.v9i4A.3490

*Address for Correspondence:

Pakhale Nilesh.V, Department of pharmaceutics, R.G. Sapkal College of pharmacy, Anjaneri, Nashik-422213, Maharashtra, India

\section{INTRODUCTION}

Oral drug administration still remains the route of choice for the majority of clinical applications some drug have ideal characteristics for good absorption to occur desirable for optimizing the therapeutic benefit of the drug ${ }^{1}$. Oral delivery of drugs is by far the most preferable route of drug delivery due to the ease of administration, patient compliance and flexibility in formulation ${ }^{2}$. Attempts have been made to be 8 $10 \mathrm{hr}$. From mouth to colon, is relatively brief with considerable fluctuation. One of the important determinants of G.I transit is the residence time in the stomach. The oral controlled delivery of drugs having "absorption window" continually releasing the drug prior to absorption window for prolonged period of time, thus ensuring optimal bioavailability ${ }^{3}$. A floating dosage unit is useful for drugs acting locally in the proximal gastrointestinal tract. These systems are also useful for drugs that are poorly soluble or unstable in intestinal fluids. Floating tablets and Floating capsules are common examples of floating system ${ }^{4,5}$.

\section{Effervescent Floating Drug Delivery System:}

A gastro retentive dosage form will release the drug over an extended period in the stomach and upper gastrointestinal tract (GIT) thus enhancing the opportunity for absorption.
Various approaches have been proposed to control the gastric residence of drug delivery system in the upper part of the GIT including floating drug delivery system. High density DDS, bioadhesive systems, swelling and expanding DDS, modified shape systems and other delayed gastric devices ${ }^{5,6}$. FDDS is suitable for drugs with an absorption window in the stomach or the upper small intestine, for drugs which act locally in the stomach and for drugs that are poorly soluble or unstable in the intestinal fluid DDS or hydro dynamically balanced systems have a bulk density lower than gastric fluid and thus remain buoyant in the stomach without affecting the gastric emptying rate for a prolonged period of time. Based on the mechanism of buoyancy, two distinctly different technologies, i.e. noneffervescent and effervescent systems, have been used in the development of FDDS6,7,8.

The effervescent system uses matrices prepared with swellable polymers and effervescent components e.g. sodium bicarbonate and citric acid or stearic acid. In noneffervescent FDDS, the drug mixes with a gel forming hydrocolloid, which swells in contact with gastric fluid after oral administration to maintain a relatively stable shape and a bulk density of less than unity within the outer gelatinous barrier9. 


\section{MATERIAL AND METHOD}

\section{MATERIAL}

\section{Preformulation Study of Drug:}

Preformulation testing is the first step in the rational development of dosage forms of a drug. It can be defined as an investigation of physical and chemical properties of drug substance, alone and when combined with excipients. The overall objective of preformulation testing is to generate information useful to the formulator in developing stable and bioavailable dosage forms, which can be massproduced ${ }^{10,11}$.

\section{Identification Tests}

\section{a) Organoleptic Properties:}

The sample of Fluoxetine was studied for organoleptic characteristics such as colour, odour and appearance ${ }^{10,11 .}$

\section{b) Melting Point:}

Melting point of Fluoxetine was determined by taking a small amount of sample in a capillary tube closed at one end and placed in melting point apparatus. The melting point was noted in triplicate and average value was noted ${ }^{10,11}$.

\section{c) IR Spectroscopy}

The FT-IR spectrum of the obtained sample of drug was compared with the standard FT-IR spectra of the pure drug.

\section{d) Solubility analysis:}

Preformulation solubility analysis was done to select a suitable solvent system to dissolve the drug and also to test its solubility in the dissolution medium which was to be used.

\section{e) Differential Scanning Calorimetry:}

The powdered sample (3 mg) was hermetically sealed in aluminium pans and heated at a constant rate $10^{\circ} \mathrm{C} / \mathrm{min}$, over a temperature range of $30-300^{\circ} \mathrm{C}$ with nitrogen flow rate of $30 \mathrm{ml} / \mathrm{min}$. Thermograms of the samples were obtained using differential scanning Calorimetry (DSC-60, Shimadzu, Japan). Thermal analysis data were recorded with Shimadzu software programs. Indian standard was to calibrate the DSC temperature and enthalpy scale.

\section{Compatibility studies}

\section{a) IR Spectroscopy}

Compatibility study was carried out by using Fourier Transform Infrared Spectrophotometer (BRUCKER). IR study was carried on pure drug. Physical mixture of drug and excipients were prepared and samples kept for 1 month at $40^{\circ} \mathrm{C}$. The infrared absorption spectrum of Fluoxetine and physical mixture of drug and excipient was recorded using diamond disc 12,13 .

\section{b) Preparation of 0.1 N HCL}

$8.5 \mathrm{ml}$ of concentrated HCL was taken and diluted with distilled water up to $1000 \mathrm{ml}$.

\section{c) Preparation of Standard Calibration curve of Fluoxetine}

The UV spectrum of Fluoxetine was obtained by using UV (Shimadzu UV - 1800, Japan). Accurately weighed $10 \mathrm{mg}$ of the drug was dissolved in sufficient quantity of $0.1 \mathrm{~N} \mathrm{HCl}$ and volume made up to $10 \mathrm{ml}$. The stock solution was diluted to obtain a concentration of $100 \mu \mathrm{g} / \mathrm{ml} .1 \mathrm{ml}$ of aliquot was withdrawn and volume was made up to $10 \mathrm{ml}$ using $0.1 \mathrm{~N}$ $\mathrm{HCl}$ to obtain the concentration of $10 \mu \mathrm{g} / \mathrm{ml}$. The resultant solution was scanned from 400 to $200 \mathrm{~nm}$ and the spectrum was recorded to obtain the value of maximum Wavelength in respective solvents ${ }^{10,11}$.

Formulation and Preparation of Effervescent Floating of Fluoxetine tablet by direct compression

Weight all the ingredient accurately fist add polymer HPMC K4M in mortar then Carbopol 934 \& Sodium bicarbonate mix it well for $10 \mathrm{~min}$ then add drug , magnesium stearate \& lactose blend for $10 \mathrm{~min}$ at the last magnesium stearate $1 \%$ add mix all ingredient homogenously to form a tablet mix for direct compression ${ }^{14}$.

\section{Evaluation of powder}

The flow properties of granules (before compression) were characterized in terms of angle of repose, tapped density, bulk density, Carr's index and Hausner's ratio $3,4,15$.

Table No 2: Formulation Chart of Effervescent Floating Tablet of Fluoxetine

\begin{tabular}{|c|c|c|c|c|c|c|c|c|c|}
\hline Ingredients & \multicolumn{10}{c|}{ Formulation code } \\
\hline Quantity (mg) & F1 & F2 & F3 & F4 & F5 & F6 & F7 & F8 & F9 \\
\hline Fluoxetine & 75 & 75 & 75 & 75 & 75 & 75 & 75 & 75 & 75 \\
\hline HPMC K4M & 50 & 50 & 50 & 60 & 60 & 60 & 70 & 70 & 70 \\
\hline Carbopol 934 & 10 & 15 & 20 & 10 & 15 & 20 & 10 & 15 & 20 \\
\hline $\begin{array}{c}\text { Sodium } \\
\text { Bicarbonate }\end{array}$ & 30 & 30 & 30 & 30 & 30 & 30 & 30 & 30 & 30 \\
\hline Citric acid & 10 & 10 & 10 & 10 & 10 & 10 & 10 & 10 & 10 \\
\hline Mg Stearate & 3 & 3 & 3 & 3 & 3 & 3 & 3 & 3 & 3 \\
\hline Lactose & 47 & 42 & 37 & 37 & 32 & 27 & 27 & 22 & 17 \\
\hline Total Weight & 225 & 225 & 225 & 225 & 225 & 225 & 225 & 225 & 225 \\
\hline
\end{tabular}

\section{Determination of Swelling Index:}

The swelling properties of matrices containing drug were determined by placing tablet matrices in the dissolution test apparatus in $900 \mathrm{ml} 0.1 \mathrm{~N} \mathrm{HCl}$ at $37 \pm 0.5^{\circ} \mathrm{C}$. The tablets were removed periodically from the dissolution medium and, after removing free water, the weight gain was measured. The swelling characteristics were expressed in terms of the percentage water uptake (WU \%) according to the equation 5 . ISSN: 2250-1177

\section{Determination of Floating capacity:}

Three individual tablets from each formulation were put in an individual flask containing $400 \mathrm{ml}$ of $0.1 \mathrm{~N} \mathrm{HCl}$ solutions. Then note time in minutes for each tablets to go from the bottom to the top of the flask (floating lag time) and the time for which tablets constantly float on the water surface (duration of floating) were measured. The sample mean and standard deviation were calculated. 


\section{In-vitro Disintegration Time:}

Disintegration time was determined using USP disintegration apparatus with distilled water. The volume of medium was $900 \mathrm{ml}$ and temperature was $37 \pm 0.2^{\circ} \mathrm{C}$. The time in minutes taken for complete disintegration of the tablet with no palatable mass remaining in the apparatus was measured. To comply the test all tablets should disintegrate within 15 minutes.

\section{Drug Content:}

Units were selected at random and drug content was determined as specified in monograph. The tablet preparation complies with the test, only if each individual content lies between 85 to $115 \%$ of the average content ${ }^{4}$.

\section{In Vitro drug release kinetics studies}

Kinetic model had described drug dissolution from solid dosage form where the dissolved amount of drug is a function of test time. In order to study the exact mechanism of drug release from the tablets, drug release data was analyzed according to zero orders, first order, Higuchi square root, korsmeyer peppas model.

\section{RESULT AND DISCUSSION}

\section{Compatibility study by IR spectroscopy}

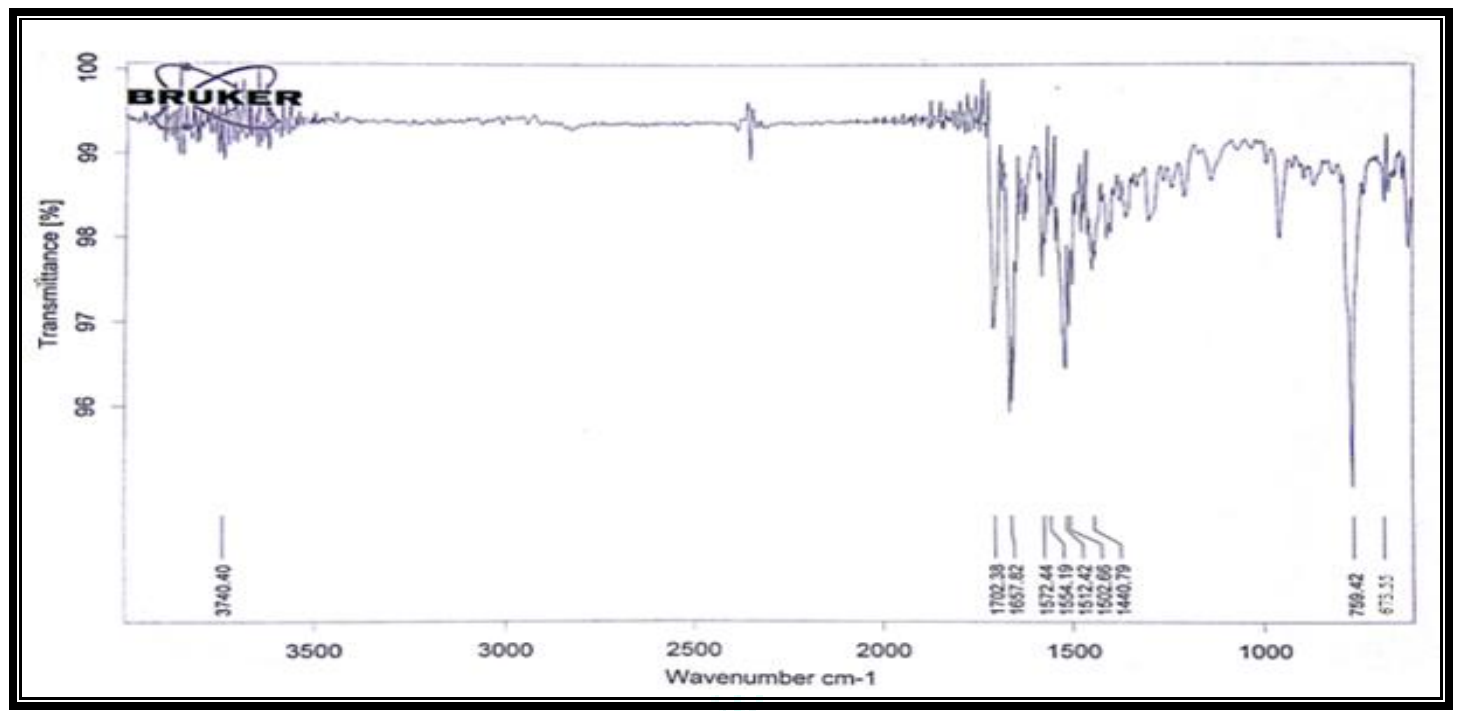

Figure 2: FTIR Spectrum of Fluoxetine

The FTIR spectra of pure Fluoxetine showed the peaks at wave numbers $\left(\mathrm{cm}^{-1}\right)$ which correspond to the functional groups present in the structure of the drug.

\section{Differential Scanning Calorimetry:-}

The powdered sample (3mg) was hermetically sealed in aluminium pans and heated at a constant rate $100 \mathrm{C} / \mathrm{min}$ over a temperature range of $30-3000 \mathrm{C}$ with nitrogen flow rate of $30 \mathrm{ml} / \mathrm{min}$. Thermograms of the samples were obtained using differential scanning Calorimetry (DSC-60, Shimadzu, Japan). Thermal analysis data were recorded with Shimadzu software programs. Indian standard was to calibrate the DSC temperature and enthalpy scale

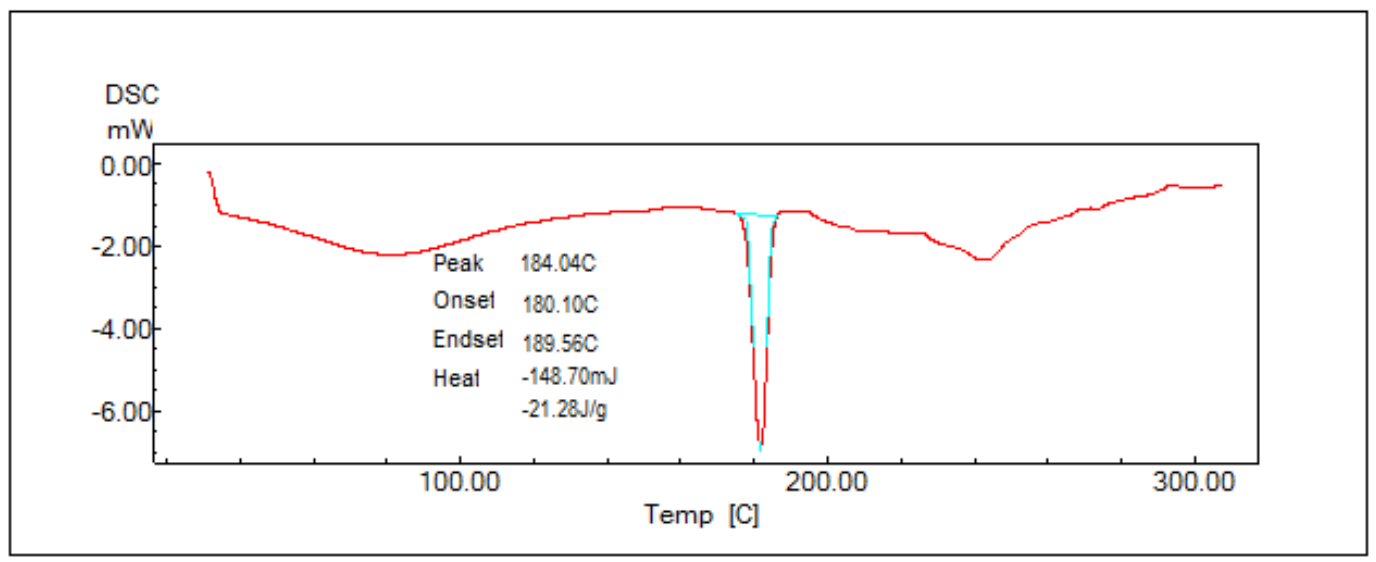

Fig.DSC Thermogram of Fluoxetine 


\section{Evaluation of Formulation:}

The Fluoxetine tablets were prepared by direct compression method. Ingredients were accurately weighed and passed through mesh. The powder blend was studied for rheological characteristics. The uniformly blend of powder was then compressed in a 10 station tablet punching machine using $12 \mathrm{~mm}$ flat faced punches ${ }^{16}$.

Before compression powder bed of all formulations were studied for various rheological characteristics bulk density, true density, compressibility index, Hausner's ratio. The results of the studies indicated that the powder bed is easily compressible, and hence can be compressed into a compact mass of tablets. The angle of repose is an indicative parameter of powder Flowability from hopper to die cavity ${ }^{17}$.

A repose angle between $25^{0}$ to $30^{\circ}$ indicates excellent Flowability of powder bed. In this work, the angle of repose was found to be varying between $22.81^{\circ}$ and $26.72^{\circ}$ when glidants were incorporated. These studies indicated that, the powder beds of all formulations are easily flowable.

\section{Evaluation of Pre-compressed parameters:}

All formulations were studied for various rheological characteristics bulk density, true density, compressibility index, Hausner's ratio and angle of repose. The results of the studies indicated that the powder is blend is easily compressible.

Table 3: Pre-Compressed Evaluations

\begin{tabular}{|c|c|c|c|c|c|}
\hline $\begin{array}{c}\text { Formulation } \\
\text { code }\end{array}$ & $\begin{array}{c}\text { Bulk density } \\
\text { (gm/ml) }\end{array}$ & $\begin{array}{c}\text { Tapped density } \\
\text { (gm/ml) }\end{array}$ & $\begin{array}{c}\text { Angle of } \\
\text { Repose ( } \boldsymbol{\theta})\end{array}$ & $\begin{array}{c}\text { Compressibility } \\
\text { index (\%) }\end{array}$ & $\begin{array}{c}\text { Hausner's } \\
\text { ratio }\end{array}$ \\
\hline F1 & $0.354 \pm 0.0030$ & $0.411 \pm 0.0030$ & $21.27 \pm 0.54$ & $18.27 \pm 0.16$ & $1.22 \pm 0.013$ \\
\hline F2 & $0.363 \pm 0.0021$ & $0.427 \pm 0.0046$ & $22.62 \pm 0.51$ & $12.01 \pm 0.14$ & $1.14 \pm 0.005$ \\
\hline F3 & $0.354 \pm 0.0033$ & $0.418 \pm 0.0092$ & $24.63 \pm 0.46$ & $6.23 \pm 0.39$ & $1.11 \pm 0.008$ \\
\hline F4 & $0.347 \pm 0.0039$ & $0.453 \pm 0.0024$ & $24.57 \pm 0.53$ & $9.02 \pm 0.52$ & $1.13 \pm 0.006$ \\
\hline F5 & $0.373 \pm 0.0041$ & $0.442 \pm 0.0026$ & $27.82 \pm 0.51$ & $13.75 \pm 0.68$ & $1.23 \pm 0.009$ \\
\hline F6 & $0.377 \pm 0.0019$ & $0.410 \pm 0.0025$ & $27.64 \pm 0.44$ & $12.03 \pm 0.29$ & $1.13 \pm 0.003$ \\
\hline F7 & $0.385 \pm 0.0036$ & $0.458 \pm 0.0062$ & $26.29 \pm 0.43$ & $15.13 \pm 0.49$ & $1.19 \pm 0.007$ \\
\hline F8 & $0.356 \pm 0.0035$ & $0.442 \pm 0.0054$ & $29.35 \pm 0.52$ & $16.80 \pm 0.77$ & $1.17 \pm 0.024$ \\
\hline F9 & $0.389 \pm 0.0024$ & $0.467 \pm 0.0040$ & $29.53 \pm 0.55$ & $13.91 \pm 0.13$ & $1.16 \pm 0.016$ \\
\hline
\end{tabular}

\section{Evaluation of Post Compressed Characteristics:}

The results of Hardness, Disintegration time, Drug content, Friability, Swelling index, Floating time all are summarized in the table given below:

Table 4: Post-Compressed Evaluations

\begin{tabular}{|c|c|c|c|c|c|c|}
\hline $\begin{array}{l}\text { Formulati } \\
\text { on code }\end{array}$ & $\begin{array}{c}\text { Hardness } \\
\left(\mathrm{kg} / \mathrm{cm}^{2}\right) \pm \\
\text { S.D. }\end{array}$ & $\begin{array}{c}\text { Drug content } \\
(\%) \pm \text { S.D. }\end{array}$ & $\begin{array}{l}\text { (\%) Friability } \\
\pm \text { S.D. }\end{array}$ & $\begin{array}{l}\text { Swelling } \\
\text { index } \%\end{array}$ & $\begin{array}{l}\text { Thickness } \\
\text { (mm) }\end{array}$ & $\begin{array}{c}\text { Weight } \\
\text { Variation } \\
\text { (mg) }\end{array}$ \\
\hline F1 & $3.32 \pm 0.057$ & $97.35 \pm 0.040$ & $0.174 \pm 0.037$ & $34.07 \pm 0.69$ & $3.69 \pm 0.63$ & $224.13 \pm 1.5$ \\
\hline F2 & $3.47 \pm 0.034$ & $95.00 \pm 0.029$ & $0.263 \pm 0.035$ & $45.51 \pm 0.77$ & $3.83 \pm 0.13$ & $223.61 \pm 0.03$ \\
\hline F3 & $3.56 \pm 0.072$ & $98.42 \pm 0.020$ & $0.276 \pm 0.081$ & $58.55 \pm 0.90$ & $3.94 \pm 0.21$ & $224.09 \pm 0.03$ \\
\hline F4 & $3.39 \pm 0.059$ & $99.79 \pm 0.045$ & $0.341 \pm 0.143$ & $45.22 \pm 0.75$ & $3.96 \pm 0.40$ & $224.5 \pm 0.028$ \\
\hline F5 & $3.50 \pm 0.050$ & $98.61 \pm 0.017$ & $0.358 \pm 0.049$ & $47.70 \pm 0.65$ & $3.96 \pm 0.64$ & $225.17 \pm 1.69$ \\
\hline F6 & $3.48 \pm 0.079$ & $97.53 \pm 0.016$ & $0.362 \pm 0.028$ & $41.88 \pm 0.44$ & $3.94 \pm 0.19$ & $225.12 \pm 0.16$ \\
\hline F7 & $3.43 \pm 0.088$ & $99.22 \pm 0.028$ & $0.531 \pm 0.054$ & $46.07 \pm 0.67$ & $3.93 \pm 0.67$ & $224.8 \pm 0.018$ \\
\hline F8 & $3.47 \pm 0.05$ & $96.65 \pm 0.031$ & $0.554 \pm 0.37$ & $47.25 \pm 2.10$ & $3.91 \pm 0.29$ & $224 \pm 0.018$ \\
\hline F9 & $3.79 \pm 0.03$ & $98.14 \pm 0.029$ & $0.615 \pm 0.42$ & $49.40 \pm 0.56$ & $3.93 \pm 0.10$ & $225.35 \pm 0.25$ \\
\hline
\end{tabular}




\section{In-Vitro Floating duration}

Table 5: Floating duration time and Floating lag time

\begin{tabular}{|c|c|c|c|c|c|c|c|c|c|}
\hline Formulation code & F1 & F2 & F3 & F4 & F5 & F6 & F7 & F8 & F9 \\
\hline Floating time (hr.) & 12 & 12 & 12 & 12 & 12 & 12 & 12 & 12 & 12 \\
\hline Floating lag time (sec) & 55 & 68 & 80 & 104 & 122 & 151 & 166 & 212 & 224 \\
\hline
\end{tabular}

\subsubsection{In Vitro drug release studies:}

The dissolution studies were carried out for all nine formulations (i.e. F1 to F9)

Table 6: Percent Cumulative drug release of different Formulations (F1-F9)

\begin{tabular}{|c|l|l|l|l|l|l|l|l|l|}
\hline $\begin{array}{l}\text { Time } \\
\text { (hr.) }\end{array}$ & \multicolumn{1}{|c|}{ F1 } & \multicolumn{1}{|c|}{ F2 } & \multicolumn{1}{|c|}{ F3 } & \multicolumn{1}{|c|}{ F5 } & \multicolumn{1}{|c|}{ F6 } & \multicolumn{1}{|c|}{ F8 } & F9 \\
\hline $\mathbf{1}$ & 6.36 & 6.64 & 7.57 & 9.12 & 7.78 & 8.84 & 8.06 & 4.90 & 5.70 \\
& \pm 1.98 & \pm 5.95 & \pm 2.15 & \pm 2.42 & \pm 2.06 & \pm 1.90 & \pm 2.02 & \pm 2.10 & \pm 1.53 \\
\hline $\mathbf{2}$ & 17.29 & 21.68 & 19.27 & 15.79 & 16.43 & 16.67 & 15.58 & 10.15 & 10.57 \\
& \pm 2.38 & \pm 1.93 & \pm 2.25 & \pm 1.74 & \pm 2.83 & \pm 2.32 & \pm 4.11 & \pm 2.04 & \pm 2.08 \\
\hline $\mathbf{3}$ & 25.42 & 27.57 & 25.14 & 25.34 & 19.06 & 23.18 & 17.46 & 19.25 & 12.86 \\
& \pm 2.06 & \pm 1.83 & \pm 2.05 & \pm 2.31 & \pm 1.99 & \pm 2.501 & \pm 2.05 & \pm 2.07 & \pm 2.84 \\
\hline $\mathbf{4}$ & 35.88 & 31.58 & 32.99 & 31.70 & 21.81 & 29.81 & 18.03 & 24.45 & 23.46 \\
& \pm 2.52 & \pm 2.54 & \pm 2.21 & \pm 1.58 & \pm 2.61 & \pm 2.49 & \pm 2.56 & \pm 2.83 & \pm 2.01 \\
\hline $\mathbf{5}$ & 39.84 & 39.84 & 40.14 & 42.31 & 25.34 & 36.72 & 22.24 & 30.41 & 30.41 \\
& \pm 1.87 & \pm 2.22 & \pm 1.94 & \pm 2.41 & \pm 1.91 & \pm 1.92 & \pm 1.93 & \pm 1.95 & \pm 1.90 \\
\hline $\mathbf{6}$ & 46.40 & 48.55 & 48.55 & 47.24 & 28.29 & 38.05 & 33.08 & 37.90 & 39.25 \\
& \pm 2.02 & \pm 2.39 & \pm 2.11 & \pm 2.15 & \pm 2.15 & \pm 1.9 & \pm 2.07 & \pm 1.90 & \pm 1.89 \\
\hline $\mathbf{7}$ & 55.16 & 57.31 & 57.39 & 53.01 & 31.84 & 45.69 & 36.87 & 45.43 & 47.58 \\
& \pm 2.10 & \pm 2.62 & \pm 1.99 & \pm 1.94 & \pm 1.95 & \pm 2.34 & \pm 2.00 & \pm 1.43 & \pm 4.95 \\
\hline $\mathbf{8}$ & 61.10 & 65.66 & 68.37 & 62.00 & 43.97 & 49.72 & 45.22 & 53.01 & 50.86 \\
& \pm 2.04 & \pm 2.19 & \pm 2.04 & \pm 2.17 & \pm 2.06 & \pm 2.06 & \pm 2.15 & \pm 2.11 & \pm 2.47 \\
\hline $\mathbf{9}$ & 64.98 & 73.26 & 75.24 & 69.41 & 54.99 & 65.32 & 53.29 & 62.43 & 55.16 \\
& \pm 2.07 & \pm 2.04 & \pm 2.54 & \pm 2.00 & \pm 2.00 & \pm 1.98 & \pm 2.01 & \pm 1.92 & \pm 1.81 \\
\hline $\mathbf{1 0}$ & 71.44 & 80.21 & 82.71 & 76.94 & 64.87 & 76.74 & 65.36 & 70.44 & 59.30 \\
& \pm 2.64 & \pm 2.03 & \pm 2.36 & \pm 1.86 & \pm 1.63 & \pm 2.45 & \pm 2.56 & \pm 1.36 & \pm 1.56 \\
\hline $\mathbf{1 1}$ & 76.73 & 79.53 & 86.63 & 79.53 & 82.36 & 83.18 & 70.61 & 75.90 & 65.37 \\
& \pm 2.42 & \pm 2.69 & \pm 1.96 & \pm 2.62 & \pm 1.25 & \pm 2.48 & \pm 2.00 & \pm 2.33 & \pm 2.06 \\
\hline $\mathbf{1 2}$ & 79.53 & 84.48 & 96.35 & 81.72 & 89.63 & 88.82 & 87.43 & 77.87 & 69.97 \\
& \pm 2.48 & \pm 2.09 & \pm 2.08 & \pm 2.08 & \pm 1.98 & \pm 2.63 & \pm 2.53 & \pm 1.88 & \pm 1.32 \\
\hline
\end{tabular}

\section{Appearance}

The developed formulation met all the pre-requisite to become a floating effervescent tablet, swelled and floated instantaneously at the acidic condition of the stomach.

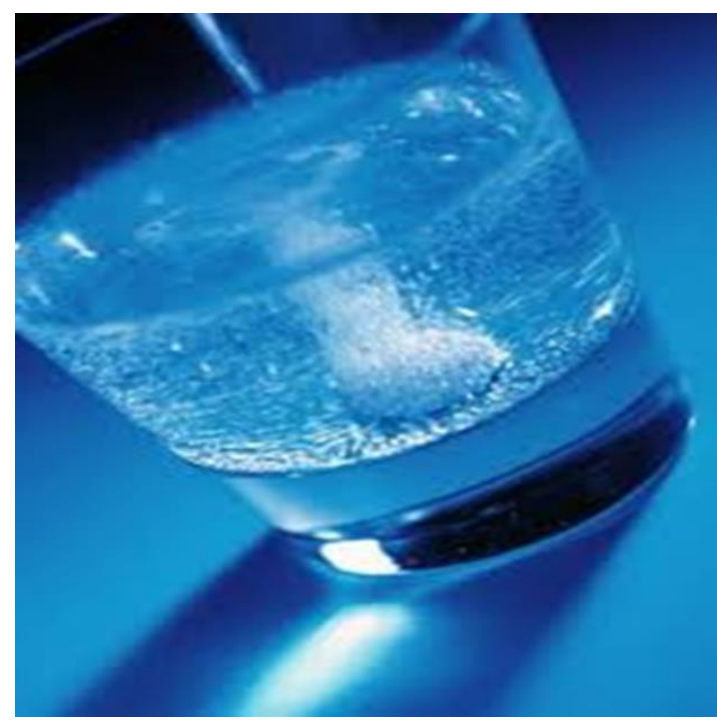

Figure 3: Effervescent Floating tablet Formulation 
In-Vitro release study

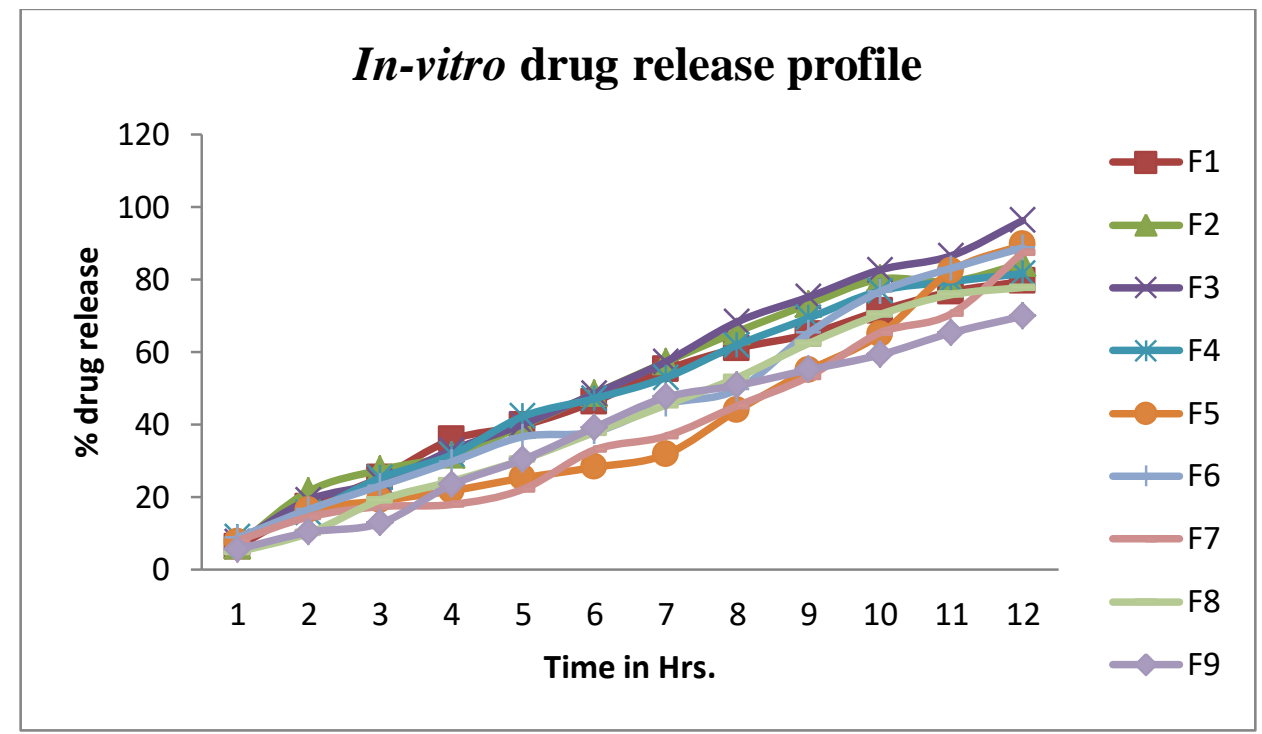

Figure 4: Dissolution Profile of Formulation Batches (F1-F9) (Time Vs \%CDR)

A) Surface Response Plots:

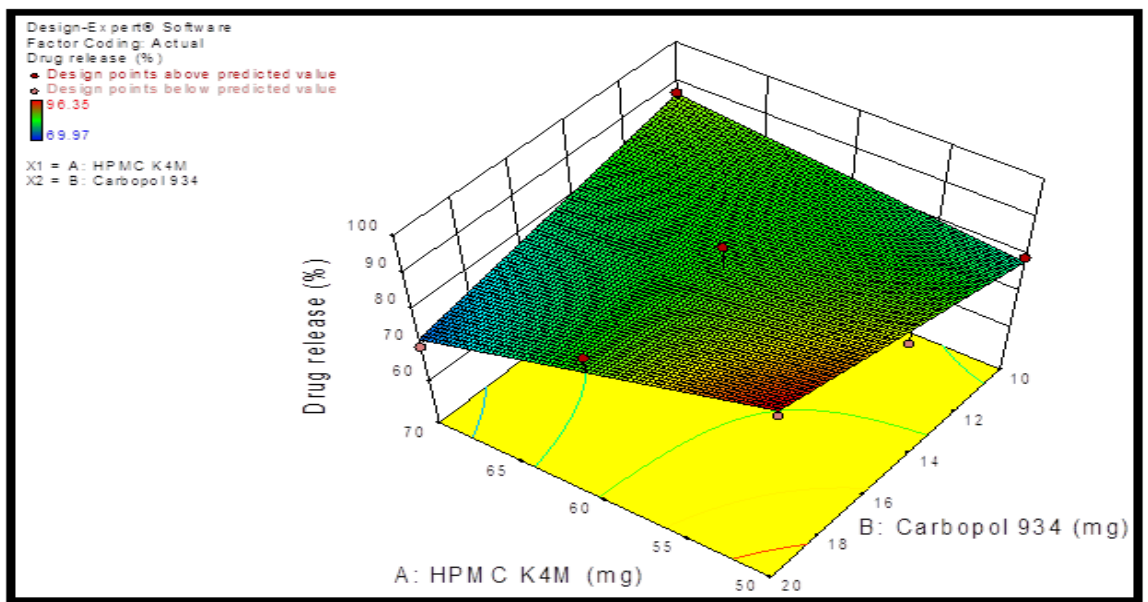

Figure 5: Surface Response plot showing effect of Carbopol 934 and HPMC K4M on drug release

B) Contour plot:

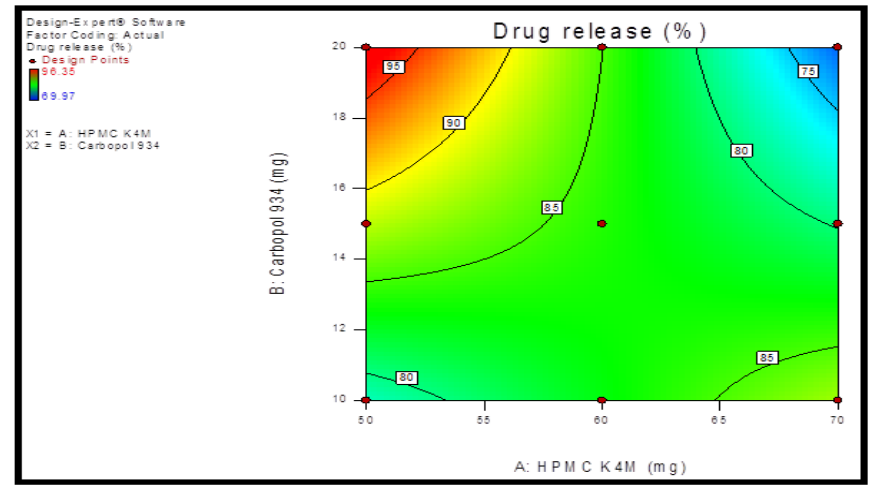

Figure 8: Contour plot showing effect of Carbopol 934 and HPMC K4M on drug release.

\section{Drug release kinetics}

In the present study, the drug release was analysed to study the kinetic of drug release mechanism. The results showed that the factorial design batches followed zero order and first order model kinetics, Higuchi and Connor's model kinetics and kosemeyer's peppas model kinetics $20,21,22$. 
Zero-order comparative evaluation model kinetics:

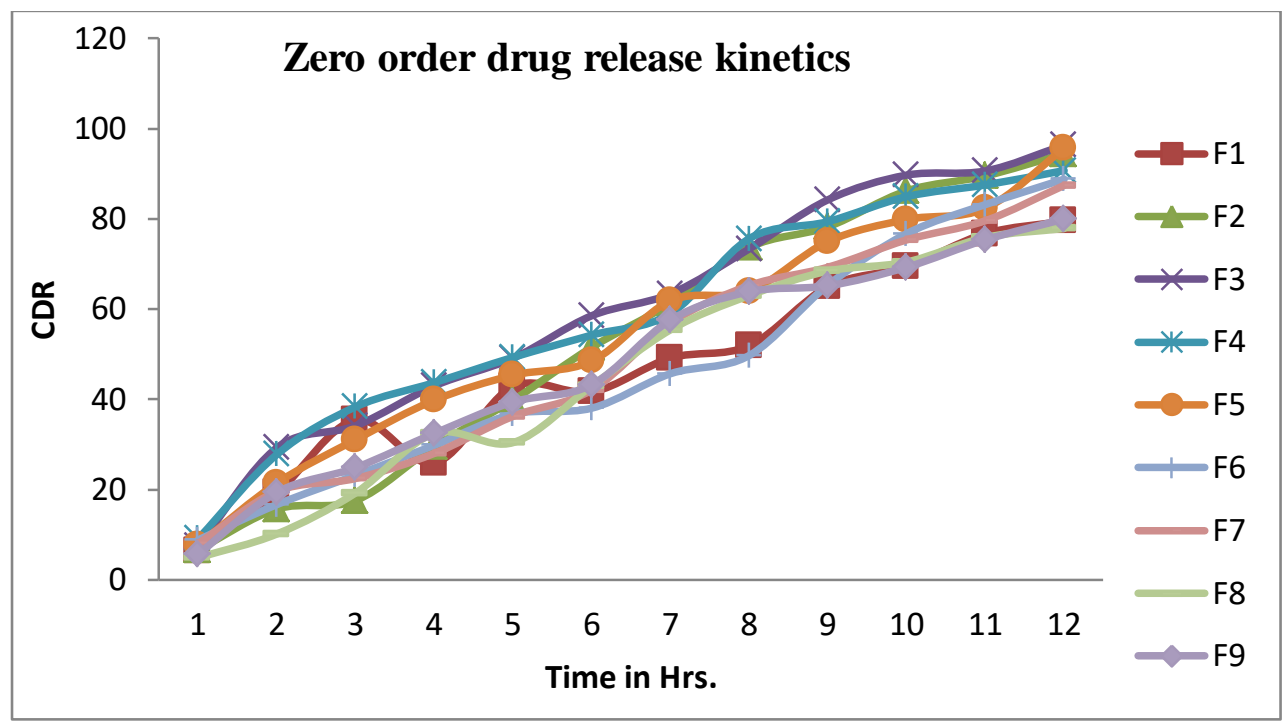

Figure 14: Model graph for comparative evaluation of zero order release kinetics

First-order comparative evaluation model kinetics:

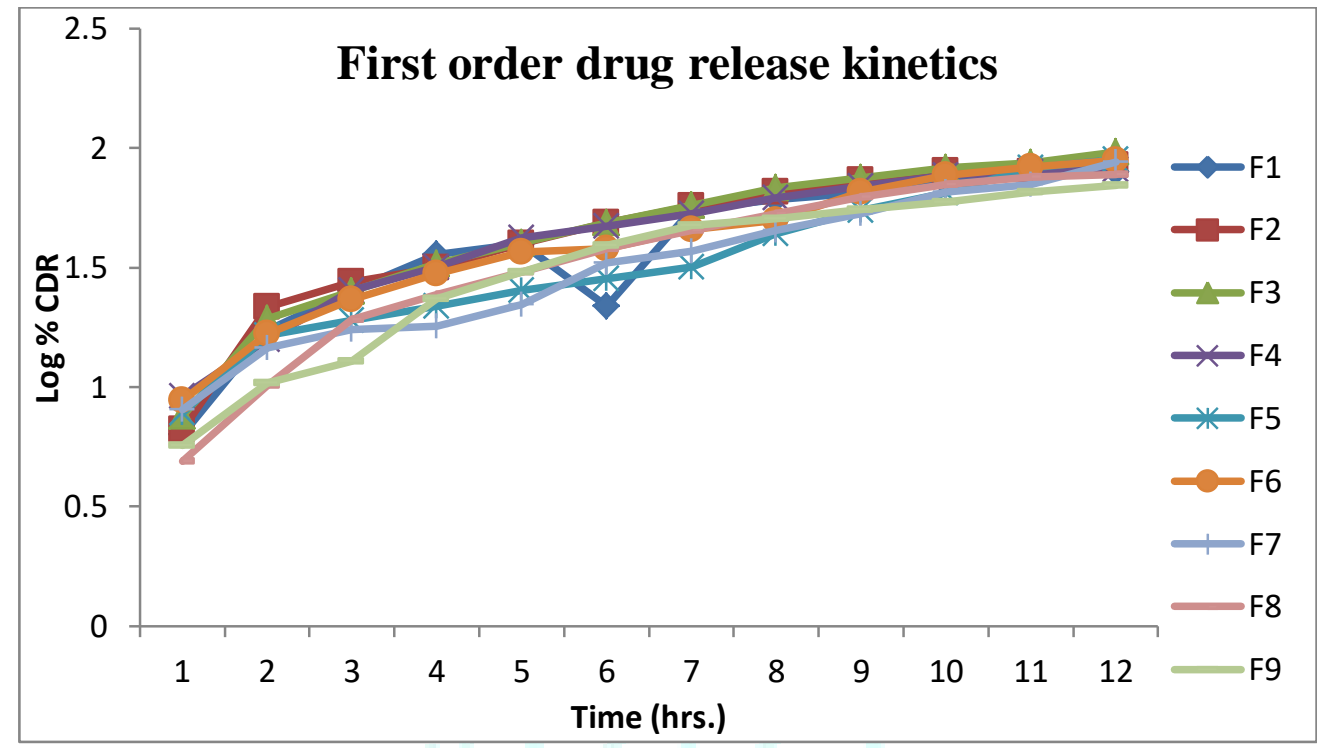

Figure 15: Model graph for comparative evaluation of First order release kinetics

Higuchi and Connor's model release kinetics:

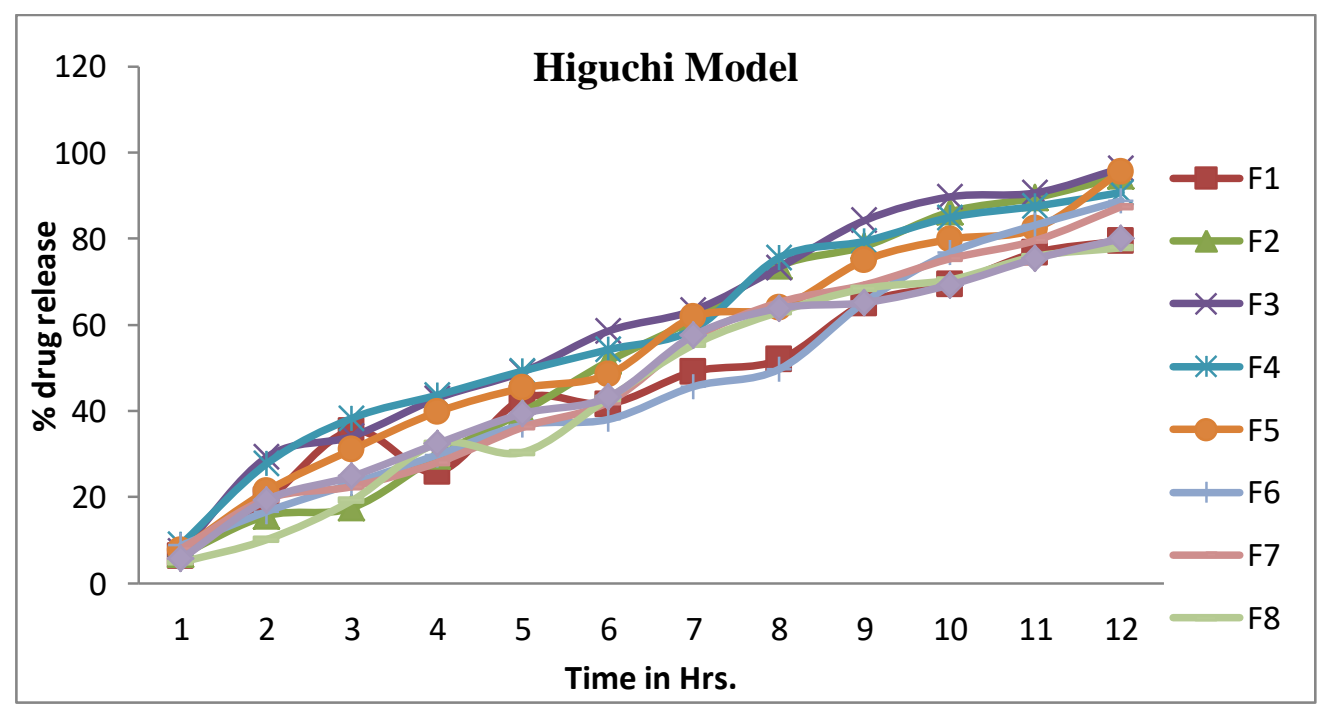

Figure 16: Model graph for comparative evaluation of Higuchi Connor's release kinetics 
Korsemeyer's peppas comparative evaluation model kinetics:

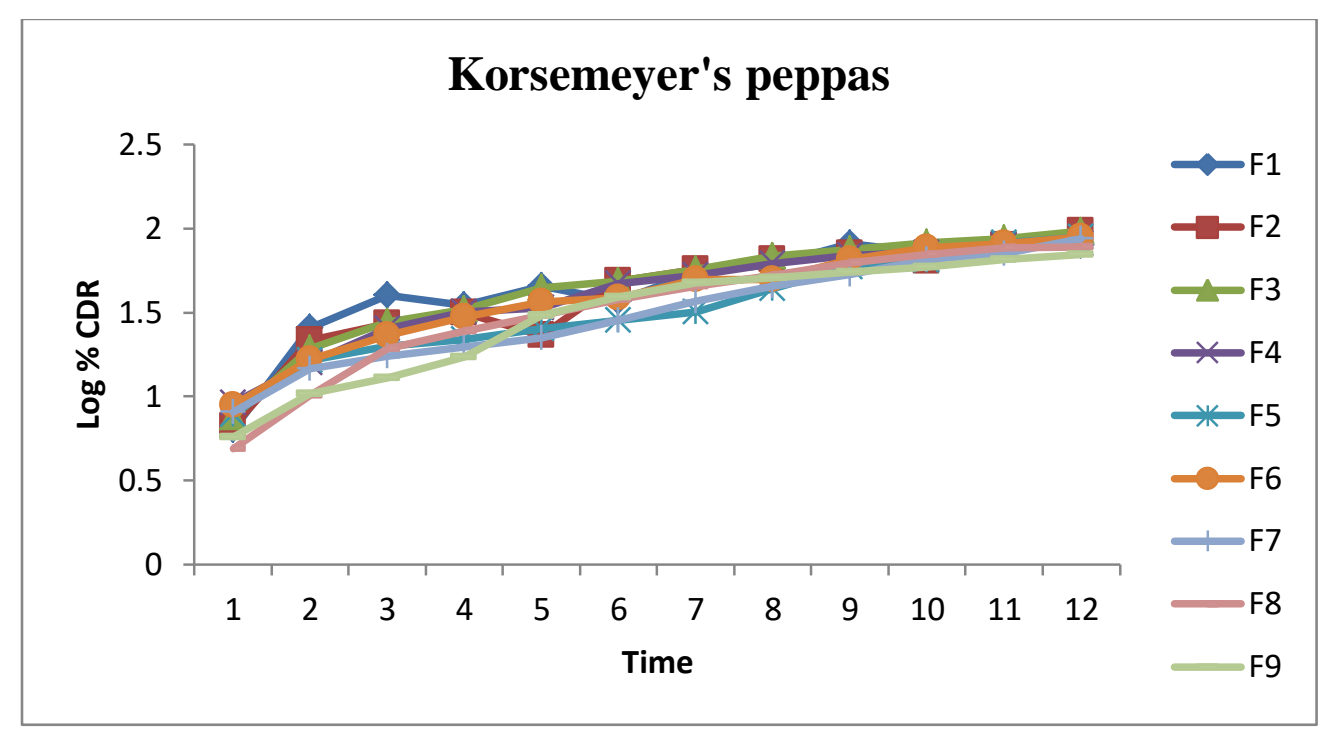

Figure 17: Model graph for comparative evaluation of Korsemeyer's peppas release kinetics

Stability Studies:

Table 8: Stability study for optimized formulation F3 at $40 \pm 2{ }^{\circ} \mathrm{C}+75 \% \mathrm{RH}$

\begin{tabular}{|c|c|c|c|}
\hline Formulaton code & 1 month & 2 month & 3 month \\
\hline F3 & $98.41 \% \pm 0.018$ & $97.94 \% \pm 0.060$ & $97.53 \% \pm 0.032$ \\
\hline
\end{tabular}

The selected formulation were wrapped in aluminium foil and stored at $40 \pm 2^{\circ} \mathrm{C}$ and $\% \mathrm{RH} 75 \% \pm 5 \%$ temperature for 3 months. After 3 months the formulation F3were evaluated for the hardness, drug content and in-vitro \% drug release. It was observed that there was no significant variation in the physical appearance, average weight, hardness and loss of drying after placing the tablets at various temperature and humidity conditions for a period of 3 months. Also the cumulative \% drug release data showed that each of the formulation released a drug amount, within the limits laid down as per the ICH guidelines for stability studies ${ }^{23}$.

\section{CONCLUSION:}

The present study was carried out to develop the effervescent floating drug delivery of fluoxetine using HPMC K4M and Carbopol 934 polymers as the carrier. Fluoxetine is BCS class I drug having high solubility and high permeability. Its oral bioavailability $55 \%$ and biological half-life is also approximately $14 \mathrm{hrs}$. All the above reason are suitable for gastro retentive drug delivery system. After procurement of drug sample it was characterized for identification by FTIR. After identification check compatibility of drug with all excipient. It was found that it is compatible with all excipient there is no change in functional group. Physical property of Fluoxetine tablet i.e. hardness, friability, average weight, thickness also complies with standard reference. Floating lag time of all nine formulation show within one minute total floating time was more than $12 \mathrm{hrs}$.

which are suitable for sustained release drug delivery system. The batch F3 shows $96.35 \%$ release in $12 \mathrm{hrs}$, so we concluded that rate of drug release increases in acidic environment of stomach. Release kinetic data of all the formulation show that F1-F9 formulation follows Korsmeyer-Peppas model. Stability study was conducted on tablets of batch F3 at $40 \pm 2^{\circ} \mathrm{C}$ for 3 months.. From the discussion it was concluded that the Tablets of batch F3 was selected as optimum batch and evaluated for stability study.

\section{REFERENCES}

1. Zawar Laxmikant R, Savaliya Pankaj J, Bari Sanjay B. Formulation Evaluation of Floating Mucoadhesive Tablet of Clarithromycin, International Journal of Pharma and Bio Sciences 2010, Pg. No.1-10.

2. Birajdar Shivprasad M, Dharveshwar J.D. Research Article of Development and Evaluation of Floating Mucoadhesive Dipyridamole Tablet, AJPRHC. Pg. No. 78-89.

3. Narang Neha. Research Article on An Updated Review on: Floating Drug Delivery System. International Journal of Applied Pharmaceutics, Vol-3, 2011, Pg. No. 1-7.

4. Lachman Leon, Lieberman H.A, The Theory and Practice of Industrial Pharmacy; CBS Publisher; Pvt. Ltd. Indian Edition 2009: 430.

5. Chien Y.W, Drugs and the pharmaceutical science, Novel Drug Delivery Systems Revised and Expanded infarma healthcare 2nd edition, 2009, Vol-50. Pg. No. 213.

6. Robinson J.R, Lee Vincent H.L, Controlled Drug Delivery Fundamentals and Applications, Drugs and the Pharmaceutical Science, informa healthcare, 2 nd edition, Vol20, Pg. No. 31, 40, 420.

7. Beckett A.H, Stenlake J.B, Practical Pharmaceutical Chemistry, Published by CBS Publishers and Distributors, UltravioletVisible Spectroscopy by Davidson A; (2007). Pg No. 279.

8. The United States Pharmacopeia, The National Formulary, The Official Compendia of Standards; USP-38, Vol- II, 2015, Pg. No. 2899, 2903.

9. Rang H.P, Dale M.M, Rang and Dale's, Pharmacology, Sixth Edition, Published by Elsevier Churchill Livingstone liberty of congress, British; 2007, Pg.N.340-343.

10. Pavia D.L, Lampman G.M, Kriz G.S, James R.V, "Spectroscopy”, 9th Indian Ed. Cennage Learning Pvt. Ltd. 2007. Pg. No. 26, 34 35, 44, 87, 97, 637.

11. Aulton M. E. Aulton's Pharmaceutics; The Design and Manufacture of Medicines, Elsevier, Churchill Livingstone: Edinburgh, 3rd edition, 2007, Pg. No. 498.

12. Srujana V, Praveen Kumar T, Formulation and evaluation of Clopidogrel bisulphate floating Matrix Tablets, International 
Journal of Drug Development and Research, Vol-6, 2014, Pg No. 135-148.

13. The Merck Index, An Encyclopedia Of Chemicals, Drugs And Biologicals 14th Edition, Published by Merck Research Laboratory Copyright 2006 By Merck And Co. Inc. Whitehouse Station, NJ USA, Page No: 2396

14. Drug Formulations Manual Eastern Publishers, 3rd edition; 2005, Pg. No. 65.

15. Fauci A.S, Braunwald E, Harrison's Principles of Medicine 17th edition, 2008, Vol-I \& II, Pg. No. 736, 737, 1530.

16. Brahmankar D.M, Jaiswal S.B, Biopharmaceutics and pharmacokinetics A Treaties, Vallabh Prakashan; 2008 Pg. No. 356.

17. Tripathi Purnima, Khar Roop. Review Article on Floating Mucoadhesive tablet. International Journal of Research and Development in pharmacy and life sciences, Vol-1,2012, Pg. No. 1-10.

18. The United States Pharmacopeia, The National Formulary, The Official Compendia of Standards; USP-38, Vol- II, 2015, Pg. No. 2899, 2903.
19. The United States Pharmacopeia. The national formulary, Asian edition 2008; the official compendia of standard, USP31, Vol- II. Pg. No.1802-1822.

20. Leon Shargel, Alan H, Swanson L.N, Lippincott Williams and Wilkins a Wolters Kluwer Health Business, Comprenhensive Pharmacy Review 6th edition, 2007, Pg. No. 358-359, 804807.

21. Patil Pramod, Kulkarni Suresh, Ammanage Anand. Research Article of Formmulation and IN-Vitro Evaluation of Mucoadhesive Tablets of Ofloxacin using Natural Gums, 2010, Pg. No. 93-98.

22. Pavia D.L, Lampman G.M, Kriz G.S, James R.V, "Spectroscopy”, 9th Indian Ed. Cennage Learning Pvt. Ltd. 2007. Pg. No. 26, 34, $35,44,87,97,637$.

23. Lippincott Williams And Wilkins. A Wolters Kluwer compony, Remington; The Science and Practice of Pharmacy; 21st edition, a Wolters Kluwer business; B.I. Publications Pvt. Ltd. 2007. Volume-I \& II, Pg. No. 1335 